\title{
Academic stress, coping, emotion regulation, affect and psychosomatic symptoms in higher education
}

\author{
Ricardo João Teixeira ${ }^{1,2}$ (D) $\cdot$ Tânia Brandão ${ }^{3,4}$ (I) $\cdot$ Artemisa Rocha Dores ${ }^{5,6}$ (D) \\ Accepted: 16 December 2020 \\ (C) The Author(s), under exclusive licence to Springer Science+Business Media, LLC part of Springer Nature 2021
}

\begin{abstract}
This study aimed to examine the associations between perceived stress, coping, emotion dysregulation, affect and psychosomatic symptoms in higher education. Participants were 183 first-year undergraduates (84\% female) that completed the Perceived Stress Scale, the Brief-COPE, the Difficulties in Emotion Regulation Scale, the PANAS, and the Manifestations of Physical Discomfort Questionnaire. Significant gender differences were found in perceived stress and psychosomatic symptoms (both higher in women), and in coping (emotional vs. humour support strategies higher for women and men, respectively). Process analysis showed that emotion dysregulation partially mediated the association between perceived stress and affect and psychosomatic symptoms. Only positive reframing partially mediated the association between perceived stress and positive affect. Emotion dysregulation seems to play an important role in the development of negative affect and psychosomatic symptoms in higher education students. This could encourage institutions to promote developmental programs targeting emotion regulation to support students in the transition to higher education.
\end{abstract}

Keywords Academic stress $\cdot$ Coping $\cdot$ Emotion regulation $\cdot$ Affect $\cdot$ Psychosomatic symptoms $\cdot$ Higher education

\section{Introduction}

The beginning of higher education can be a particularly stressful transition for most students (e.g., Beiter et al. 2015; Othman et al. 2019). It is a developmental period in which students have to cope with a variety of stressors such as making new relationships, living apart, developing new habits of study, dealing with academic overload and colleague competition, developing new skills related to time management, and combine studies with work activities to obtain a financial

Ricardo João Teixeira

ricardojft@gmail.com

1 CINEICC, Faculty of Psychology and Educational Sciences, University of Coimbra, Rua do Colégio Novo, 3000-115 Coimbra, Portugal

2 REACH, Mental Health Clinic, Porto, Portugal

3 Department of Psychology, Autonomous University of Lisbon, Lisbon, Portugal

4 CPUP, Center for Psychology, University of Porto, Porto, Portugal

5 School of Health, Polytechnic Institute of Porto, Porto, Portugal

6 Laboratory of Neuropsychophysiology, Faculty of Psychology and Educational Sciences of University of Porto, Porto, Portugal income (Beiter et al. 2015; Sánchez-Gelabert et al. 2017; Gefen and Fish 2012). As in other developmental transitions failure on dealing with these challenges can cause psychological distress or even mental health problems. Indeed, studies have shown that levels of distress and mental health problems in university students are higher when compared with agematched community samples (e.g., Ansari et al. 2014; Larcombe et al. 2016; Stallman 2010). Moreover, gender differences have been reported with female students presenting higher levels of stress and poor quality of life than male students (e.g., Ansari et al. 2014; Eisenberg et al. 2013; Ribeiro et al. 2018; Saïas et al. 2014; Stallman 2010).

The existence of higher levels of stress among higher education students can not only impact their academic performance (e.g., Frazier et al. 2019; Stallman 2010) but also lead to higher education dropout and even to the development of psychosomatic symptoms (e.g., Ansari et al. 2014; Lee et al. 2011) and even more serious psychological disorders (e.g., Carlson and Voss 2017; Shi et al. 2015). However, little is known about such problems in the context of polytechnic higher education, namely within the field of health professions training. Some research has found that students enrolled in health degrees seem to have poorer mental health and higher levels of stress related to perfectionist standards, the demanding of healthcare practice that encompasses emotionally 
stressful situations, or even high workloads and tight time schedules (Heinen et al. 2017; Ribeiro et al. 2018), in comparison to peers studying in non-health related areas (Heinen et al. 2017).

\section{Perceived Stress, Coping and Emotion Regulation}

As stated before, higher levels of perceived stress represent a critical factor capable of affecting students' mental health and academic performance (e.g., Carlson and Voss 2017; Frazier et al. 2019). There are, however, individual differences in the way perceived stress influence these outcomes. This individual variability can be explained by the individual's resources such as coping (i.e., the cognitive and behavioural efforts a person employs to manage stress; Lazarus and Folkman 1984) and emotion regulation strategies (i.e., "the process by which individuals influence which emotions they have, when they have them, and how they experience and express these emotions" (Gross 1998 p. 275; Folkman 2010; Wranik et al. 2007). The way individuals cope with stress and regulate their emotions contribute to explain students' adaptation to stress. For instance, some studies have found that stress levels have less impact on final exams and in students' mental health when they use more adaptive coping strategies (such as active coping) (Monat et al. 2007; Suldo et al. 2008).

Concerning to emotion regulation ability, for adults who report higher scores in their ability to regulate their emotions, the impact of perceived stress on well-being and depression was smaller (Extremera and Rey 2015). Using a sample of 312 adolescents, Yildiz (2017) found that internal dysfunctional emotion regulation, assistance seeking, problem-solving, and behavioral avoidance mediated the association between perceived stress and positivity. Also, in a study with 1130 college students, it was found that more adaptive emotion regulation strategies (i.e., cognitive reappraisal) was a protective factor and less adaptative emotion regulation strategies (i.e., suppression) act as a protective and risk factor, respectively, for the effect of stress on psychosocial adjustment outcomes of emerging adults transitioning to college (Zahniser and Conley 2018).

\section{Coping, Emotion Regulation and Affect and Psychosomatic Symptoms}

Specifically, in the context of higher education, studies have shown that students who can use more adaptive coping strategies perceived challenges more effectively, perceive less stress, experience better adjustment to higher education, and report greater success overall (Abdullah et al. 2010; Enns et al. 2018; Sasaki and Yamasaki 2007). On the contrary, those students who are likely to use more maladaptive coping strategies tend to experience more negative affective outcomes and poor academic adjustment (Austin et al. 2010; Dyson and Renk 2006). Particularly, escape avoidance behaviors, including substance use, have been associated with more psychological distress in higher education students (Alzayyat and Al-Gamal 2016; Deasy et al. 2014). In a recent study, students reporting more mental health problems (such as interpersonal stress, depression, or anxiety) were those who reported to use less engagement coping strategies and more disengagement coping strategies (Coiro et al. 2017). Moreover, ineffective coping strategies may increase students' health problems, demand for health services, and attrition rates (Morrison and O'Connor 2005).

Concerning to emotion regulation, more adaptive emotion regulation skills have been linked to academic achievement and student engagement (Fernandez et al. 2012; Linnenbrink 2007). It seems to contribute to differentiate between students who remain and students who drop out of university (e.g., Parker et al. 2006). The ability to down-regulate negative emotions and up-regulate positive emotions seems to be essential for dealing with academic life stressors (e.g., Austin et al. 2010).

\section{Coping Strategies and Emotion Regulation as Mediators}

Overall, coping and emotion regulation have been found to be underlying pathways linking perceived stress or stressful life events to the development of mental health problems (e.g., Aldao et al. 2010; Compas et al. 2014). Studies have shown that the effect of perceived stress on students' mental health is closely linked to the coping strategies used by them (Gibbons et al. 2011; Seyedfatemi et al. 2007). Additionally, studies have found that emotion regulation act as an underlying mechanism linking perceived stress and life satisfaction and sleep difficulties in undergraduate students (Amaral et al. 2018; Saklofske et al. 2012).

Kadzikowska-Wrzosek (2012), using a sample of high school students, found that higher levels of perceived stress were related to more psychosomatic symptoms, but this link was moderated by self-regulation competences in the sense that in the presence of higher levels of perceived stress, state-orientated students experienced more psychosomatic symptoms than action-orientated students.

\section{The Present Study}

As noted above, a body of research has provided some support for the idea that individual resources such as coping or emotion regulation strategies may explain individual differences in the way perceived stress influence students' psychological functioning. (e.g., in terms of life satisfaction or sleep difficulties). Few studies, however, have explored the mediating role of these strategies as underlying mechanisms linking perceived stress and affect and psychosomatic symptoms. This happens particularly in the context of a less studied population - health sciences students - of the polytechnic subsystem. 
Based on the evidence presented before, this study aimed to examine the associations between academic perceived stress, coping, emotion regulation, dispositional affect and psychosomatic symptoms within the context of polytechnic higher education. Two specifics objectives were addressed: (1) to explore gender differences among study variables; (2) to examine the potential mediating role of coping and emotion regulation strategies in the link between perceived stress and affect and psychosomatic symptoms.

The following hypotheses were tested:

1. Based on previous studies we hypothesised that college women will report more perceived stress (e.g., Amaral et al. 2018; Brougham et al. 2009; Ribeiro et al. 2018), more emotion-focused coping strategies such as obtain emotional support or deny guilt (e.g., Amaral et al. 2018; Brougham et al. 2009; Chýlová and Natovová 2012), more emotion dysregulation (Lafrance Robinson et al. 2014; Weinberg and Klonsky 2009), higher negative affect (Amaral et al. 2018) and more psychosomatic symptoms (Kosmala-Anderson and Wallace 2007).

2. Based on previous studies, we hypothesised that levels of perceived stress will influence coping and emotion regulation strategies used by students which in turn will influence their affect and psychosomatic symptoms (e.g., Amaral et al. 2018; Gibbons et al. 2011; Saklofske et al. 2012; Seyedfatemi et al. 2007).

\section{Method}

\section{Participants}

The sample comprised 183 first-year undergraduates $(84 \%$ female) aged 17 to 41 years old $(M=19.09$ years, $S D=$ 2.87), from the School of Health $\|$ removed for blind review $\|$. Using MedPower (Kenny 2017), this sample size is considered sufficient to detect indirect effects (with a power of .97 and an alpha set to .05). This was a convenience sample with voluntary participation. No particular inclusion or exclusion criteria were defined. The students were enrolled in a variety of degrees such as Neurophysiology, Cardiopneumology, Anatomical Pathology, Environmental Health, Speech Therapy, Audiology, Occupational Therapy, and Physiotherapy. Participants received no compensation or incentives for participating in this study.

\section{Procedure}

After approval from the institution's Ethics Committee, a study with prospective design was conducted asking participants to complete a questionnaire during two times in the academic year. The present manuscript reports the results from Time 1. The participants completed self-report measures that included brief socio-demographic information, along with the measures presented below.

\section{Measures}

Perceived Stress The Perceived Stress Scale (PSS) (Cohen et al. 1983; Portuguese version Pais-Ribeiro and Marques 2009) is a 14-item self-report questionnaire that assesses the degree to which recent life situations are appraised as stressful. The Portuguese version (Pais-Ribeiro and Marques 2009) comprises only 13 items; one item (item 12) was deleted, considering its negative impact on the reliability of the total score. Respondents are asked to indicate how often they have felt or thought a certain way in the past month on a 5-point scale that ranges from 0 (never) to 4 (very often). Responses are then summed to indicate the level of perceived (subjective) stress. In the present study, Cronbach's alpha was .85 .

Coping The Brief COPE (Carver 1997; Portuguese version: Pais-Ribeiro and Rodrigues 2004) is a self-report questionnaire used to assess several coping behaviours and thoughts a person may have in response to a specific situation. It is made up of 14 subscales: self-distraction, active coping, denial, substance use, use of emotional support, use of instrumental support, behavioural disengagement, venting, positive reframing, planning, humour, acceptance, religion, and selfblame. After reading a situationally specific scenario, 28 coping behaviours and thoughts ( 2 items for each subscale) are rated on the frequency of use by the respondent using a scale of 1 (I haven't been doing this at all) to 4 (I've been doing this a lot). In the present sample, internal consistency for the 14 subscales ranged from .38 to .93. The scales 'active coping' $(\alpha=.46)$, 'planning' $(\alpha=.38)$, and 'self-blame' $(\alpha=.47)$ were not used in this study due to their lower internal consistencies (<.70; Nunnally and Bernstein 1994).

Emotion Dysregulation The Difficulties in Emotion Regulation Scale (DERS; Gratz and Roemer 2004; Portuguese version: Coutinho et al. 2010) was used to assess emotion dysregulation. This self-report scale includes 36 items rated on a 5-point Likert scale ranging from "almost never; $0-10 \%$ " to "almost always 91-100\%". It measures six dimensions of emotion dysregulation including: (1) non-acceptance - difficulties in accepting one's negative emotions; (2) goals - difficulties accomplishing goals when experiencing negative emotions; (3) impulse - difficulties remaining in control of one's behaviour when experiencing negative emotions; (4) awareness - lack of emotional awareness; (5) strategies - low self-efficacy for regulating negative emotions; and (6) clarity: difficulty identifying and understanding emotions. In the present sample, only the total DERS value was used $(\alpha=.92)$. 
Psychosomatic Symptoms The Physical Manifestations of Discomfort Questionnaire (PMDQ (Pais-Ribeiro 2003) is a Portuguese self-report scale containing 19 items, each describing usual psychosomatic complaints. Individuals must respond to each item in two different ways: frequency (6-point scale) and intensity (5-point scale) of symptoms. The results are considered in terms of frequency multiplied by intensity. According to the author, the scale points to four major types of psychosomatic manifestations: nervous system, respiratory system muscular system and digestive system. In the present study, only the total PMDQ value was used $(\alpha=.83)$.

Positive and Negative Affect The Positive and Negative Affect Schedule (PANAS) (Watson et al. 1988; Portuguese version: Galinha and Pais-Ribeiro 2005) was used to measure dispositional affect. This instrument instructs participants to rate to what extent they generally have experienced 20 different feelings or emotions (10 for positive affect - PA, and 10 for negative affect - NA) for the last 4 weeks using a 5-point scale. The 10-item PA scale includes adjectives such as strong, proud, and interested. The 10-item NA scale includes adjectives such as afraid, ashamed, and nervous. In this study, Cronbach's alphas were .89 for PA and .92 for NA.

\section{Data Analysis}

Data were analysed using SPSS (version 24; IBM, SPSS Inc., Chicago, IL). Descriptive statistics and bivariate correlations among study variables were calculated. Analyses of Variance (ANOVAs) for total scores and multivariate analyses of variance (MANOVAs) for subscale scores were used to examine gender differences among study variables.

The mediation models were examined using the SPSS PROCESS macro (version 3.3; Hayes 2015). A simple mediation model is a causal model in which one antecedent variable is proposed as influencing an outcome through a single intervening variable; in this model, there are two pathways by which the antecedent variable can affect the outcome (directly or indirectly through the mediator). (Hayes 2015). In this study, several models were tested separately with one independent variable (i.e., perceived stress), two mediators (coping strategies and emotion regulation) and three outcomes (positive affect, negative affect and psychosomatic symptoms). Given the high number of coping strategies, only those with a significant correlation with predictors or outcome variables were included in the analyses. Indirect effects of the independent variables on the dependent variables through the proposed mediators were tested using bootstrapping with 5000 bootstrap samples. Effects were considered significant if the $95 \%$ bias-corrected confidence intervals did not include 0 .

Additionally, and given gender differences found in preliminary analyses, we examined a moderated-mediation model in which we tested whether the indirect effect was contingent on a moderator - namely gender). Mean-centered variables were used. To probe a moderation of mediation we used the confidence interval for the index of moderated mediation (Hayes 2015).

\section{Results}

\section{Correlations}

Correlations among study variables are presented in Table 1 . As expected, we found a significant positive association between perceived stress, denial, behavioural disengagement, emotion dysregulation, negative affect and psychosomatic symptoms, and a significant negative association with positive reframing, humour and positive affect. Emotion dysregulation was positively and significantly associated with denial, self-distraction, behavioural disengagement, negative affect and psychosomatic symptoms, and negatively associated with positive reframing and positive affect. Positive affect was positively and significantly associated with positive reframing and humour and negatively associated with behavioural disengagement. Negative affect was negatively and significantly associated with positive reframing and behavioural disengagement. Finally, psychosomatic symptoms were positively and significantly associated with substance use and negative affect and negatively associated with positive reframing and positive affect.

\section{Gender Differences among Study Variables}

Significant gender differences were found in coping - use of emotional support $(F(1,181)=9.84, p<.01)$, coping - humour $(F(1,181)=4.53, p<.05)$, psychosomatic symptoms $(F(1,181)=16.66, p<.001)$ and perceived stress $(F(1,181)=9.95, p<.01)$. Women reported more use of emotional support $(M=6.56 ; S D=1.55)$ in comparison to men $(M=5.55 ; S D=1.80)$. In terms of use of humour, men $(M=$ 5.82; $S D=1.58)$ reported higher levels than women $(M=$ $5.20 ; S D=1.42)$. Women reported higher levels of psychosomatic symptoms $(M=58.75 ; S D=36.54)$ than men $(M=$ $30.00 ; S D=23.03)$. Finally, women experienced higher levels of stress $(M=26.36$; $S D=7.02)$ than men $(M=21.79$; $S D=$ 7.85). No gender differences were found for the remaining variables (see Table 2).

\section{Process Analysis}

The results for the mediation models are summarized in Table 3. Concerning coping strategies (i.e., positive reframing, denial, behavioral disengagement, humor, self-distraction, venting, and substance use) no indirect effects were found for negative affect and psychosomatic symptoms. For positive affect, perceived stress was significantly associated 
Table 1 Correlations among study variables

\begin{tabular}{|c|c|c|c|c|c|c|c|c|c|c|c|c|c|c|c|c|}
\hline & 1. & 2. & 3. & 4. & 5. & 6. & 7. & 8. & 9. & 10. & 11. & 12. & 13. & 14. & 15. & 16 \\
\hline 1. Perceived stress & - & & & & & & & & & & & & & & & \\
\hline $\begin{array}{l}\text { 2. Emotion } \\
\text { dysregulation }\end{array}$ & $.578 * *$ & - & & & & & & & & & & & & & & \\
\hline $\begin{array}{l}\text { 3. Instrumental } \\
\text { support }\end{array}$ & .025 & -.051 & - & & & & & & & & & & & & & \\
\hline $\begin{array}{l}\text { 4. Emotional } \\
\text { support }\end{array}$ & .089 & -.067 & $.476^{* *}$ & - & & & & & & & & & & & & \\
\hline 5. Religion & -.065 & -.008 & $.157 *$ & $.179 *$ & - & & & & & & & & & & & \\
\hline $\begin{array}{l}\text { 6. Positive } \\
\text { reframing }\end{array}$ & $-.242 * *$ & $-.316^{*}$ & .111 & .139 & .142 & - & & & & & & & & & & \\
\hline 7. Acceptance & -.129 & -.101 & .134 & $.154 *$ & .052 & $.379 * *$ & - & & & & & & & & & \\
\hline 8. Venting & .135 & .032 & $.239 * *$ & $.342 * *$ & -.035 & .120 & .112 & - & & & & & & & & \\
\hline 9. Denial & $.196^{*}$ & $.279 *$ & $.216^{* *}$ & .104 & $.184^{*}$ & -.007 & .047 & $.192 * *$ & - & & & & & & & \\
\hline 10. Self-distraction & .097 & $.203 * *$ & $.172 *$ & .034 & .057 & .107 & $.178 *$ & .036 & $.406 * *$ & - & & & & & & \\
\hline $\begin{array}{l}\text { 11. Behavioural } \\
\text { disengagement }\end{array}$ & $.180 *$ & $.174 *$ & -.101 & -.033 & -.026 & $-.183^{*}$ & -.026 & $-.157 *$ & $.172 *$ & $.234 *$ & - & & & & & \\
\hline 12. Substance use & .098 & .118 & -.021 & .040 & -.081 & .005 & -.016 & .029 & .058 & .126 & $.189 *$ & - & & & & \\
\hline 13. Humour & $-.168 *$ & -.120 & .045 & -.060 & .016 & $.304 * *$ & .090 & .005 & .072 & $.227 * *$ & -.015 & .050 & - & & & \\
\hline 14. Positive affect & $-.424 * *$ & $-.357 * *$ & -.029 & .039 & .033 & $.283 * *$ & .050 & -.069 & -.080 & .012 & $-.192 * *$ & -.040 & $.175^{*}$ & - & & \\
\hline 15. Negative affect & $.663 * *$ & $.565^{* *}$ & .057 & .092 & .018 & $-.160^{*}$ & -.118 & $.170 *$ & $.276^{* *}$ & $.172 *$ & .129 & $.168^{*}$ & -.042 & $-.288 * *$ & - & \\
\hline $\begin{array}{l}\text { 16. Psychosomatic } \\
\text { symptoms }\end{array}$ & $.486 * *$ & $.397 * *$ & .049 & .113 & -.050 & $-.184 *$ & -.092 & .095 & .095 & 031 & .041 & $.208 * *$ & -.143 & $-.181 *$ & $.446^{* *}$ & - \\
\hline
\end{tabular}

with positive affect (effect $=-.36 ; \mathrm{SE}=.07 ; 95 \%$ CI $[-.504$, $-.213]$ ); but only the indirect effect through positive reframing was significant (effect $=-.04 ; 95 \%$ CI $[-.013,-.000])\left(R^{2}=\right.$ 24\%) (Table 4).

We found a direct effect of perceived stress on both positive and negative affect and psychosomatic symptoms; when controlling for emotion dysregulation these associations remain significant indicating that emotion dysregulation partially mediated these associations. Bootstrap confidence intervals confirmed the indirect effect of emotion dysregulation in the association between perceived stress and negative affect $($ effect $=.19 ; 95 \% \mathrm{CI}[.096, .307])\left(R^{2}=43 \%\right)$, positive affect (effect $=-.10 ; 95 \% \mathrm{CI}[-.196,-.009])\left(R^{2}=20 \%\right)$, and psychosomatic symptoms (effect $=.50 ; 95 \%$ CI $[.027$, $1.094])\left(R^{2}=26 \%\right)$. Gender did not moderate any of the indirect effects.
Table 2 Gender differences for coping, emotional dysregulation, psychosomatic symptoms, stress and affect

\begin{tabular}{llcc}
\hline $\begin{array}{l}\text { Variables } \\
\text { Brief-COPE }\end{array}$ & $\begin{array}{l}\text { Women }(n=154) \\
\text { Mean (SD) }\end{array}$ & $\begin{array}{l}\text { Men }(n=29) \\
\text { Mean (SD) }\end{array}$ & $F(1,181)$ \\
\hline Use of instrumental support & $6.03(1.35)$ & $5.58(1.59)$ & 2.57 \\
Use of emotional support & $6.56(1.55)$ & $5.55(1.80)$ & $9.84^{* *}$ \\
Religion & $4.39(1.97)$ & $3.79(1.83)$ & 2.32 \\
Positive reframing & $6.09(1.36)$ & $5.79(1.47)$ & 1.18 \\
Acceptance & $5.77(1.23)$ & $5.82(1.33)$ & .05 \\
Venting & $5.79(1.54)$ & $5.44(1.84)$ & 1.18 \\
Denial & $3.94(1.47)$ & $3.96(1.67)$ & .00 \\
Self-distraction & $5.38(1.59)$ & $5.72(1.41)$ & 1.16 \\
Behavioral disengagement & $2.79(1.15)$ & $3.03(1.17)$ & 1.06 \\
Substance use & $2.14(.59)$ & $2.17(.53)$ & .06 \\
Humor & $5.20(1.42)$ & $5.82(1.58)$ & $4.53^{*}$ \\
DERS - Emotional dysregulation & $80.32(18.69)$ & $80.38(21.69)$ & .00 \\
PMDQ - Psychosomatic Symptoms & $58.75(36.54)$ & $30.00(23.03)$ & $16.66^{* * *}$ \\
PSS - Perceived Stress & $26.36(7.02)$ & $21.79(7.85)$ & $9.95^{* *}$ \\
PANAS - Positive Affect & $28.22(7.68)$ & $30.65(6.11)$ & 2.60 \\
PANAS - Negative Affect & $21.21(9.19)$ & $19.17(7.61)$ & 1.26 \\
\hline
\end{tabular}

$N=183 .^{*} p<.05 .^{* *} p<.01 .^{* * *} p<.001$ 
Table 3 Differences between high/low levels of emotional dysregulation

\begin{tabular}{|c|c|c|c|}
\hline Variables & $\begin{array}{l}\text { HIGH emotional dysregulation } \\
n=88 \\
\text { Mean (SD) }\end{array}$ & $\begin{array}{l}\text { LOW emotional dysregulation } \\
n=86 \\
\text { Mean (SD) }\end{array}$ & $\begin{array}{l}F \\
(1,172)\end{array}$ \\
\hline Brief-COPE & $5.96(1.45)$ & $5.95(1.39)$ & .00 \\
\hline \multicolumn{4}{|l|}{ Use of instrumental support } \\
\hline Use of emotional support & $6.29(1.78)$ & $6.53(1.53)$ & .90 \\
\hline Religion & $4.21(2.07)$ & $4.40(1.89)$ & .40 \\
\hline Positive reframing & $5.68(1.42)$ & $6.43(1.17)$ & $14.24^{* * * *}$ \\
\hline Acceptance & $5.69(1.27)$ & $5.94(1.18)$ & 1.78 \\
\hline Venting & $5.80(1.70)$ & $5.74(1.48)$ & .07 \\
\hline Denial & $4.31(1.57)$ & $3.63(1.36)$ & $9.24^{* * *}$ \\
\hline Self-distraction & $5.64(1.53)$ & $5.31(1.58)$ & 2.00 \\
\hline Behavioral disengagement & $3.09(1.30)$ & $2.55(.95)$ & $9.46^{* *}$ \\
\hline Substance use & $2.20(.71)$ & $2.10(.46)$ & 1.20 \\
\hline Humor & $5.15(1.53)$ & $5.50(1.40)$ & 2.34 \\
\hline $\begin{array}{l}\text { PMDQ - Psychosomatic } \\
\text { Symptoms }\end{array}$ & $65.93(36.85)$ & $43.06(32.20)$ & $18.95^{* * *}$ \\
\hline PSS - Perceived Stress & $29.19(5.95)$ & $21.54(6.16)$ & $69.22^{* * * *}$ \\
\hline PANAS - Positive Affect ${ }^{d}$ & $26.50(7.39)$ & $30.65(6.87)$ & $14.69^{* * *}$ \\
\hline PANAS - Negative Affect ${ }^{\mathrm{d}}$ & $25.11(9.35)$ & $16.86(6.36)$ & $46.09^{* * * *}$ \\
\hline
\end{tabular}

$N=174$ (Participants with a value equal to the median were excluded from groups). ${ }^{* * *} p<.01 .{ }^{* * * *} p<.001$

\section{Discussion}

This study aimed to explore gender differences among study variables and to examine coping and emotion dysregulation as potential mediators of the association between perceived stress and affect and psychosomatic symptoms among firstyear undergraduate students, in the particular context of Polytechnique system, particularly allied health sciences. The examination of these variables within this context is of high importance given the higher levels of perceived stress among university students (e.g., Larcombe et al. 2016; Stallman 2010) and because these higher levels of perceived stress are usually associated with students' academic performance, dropout or even the development of mental health disorders (e.g., Frazier et al. 2019; Carlson and Voss 2017). For this reason, it is important to undercover variables that may facilitate or hinder adaptation to the academic context.

The first objective of this study was to explore gender differences among study variables. We found that women were likely to experience higher levels of stress, more psychosomatic symptoms, to use more emotion focused coping strategies (i.e., use of emotional support) and to use less the humour as a coping strategy. These findings are in accordance with previous studies that found similar patterns in terms of gender differences (Amaral et al. 2018; Brougham et al. 2009; Chýlová and Natovová 2012; Kosmala-Anderson and Wallace 2007; Ribeiro et al. 2018). It is possible that women are more worried about their academic performance viewing their education as a way to accomplish their life goals; and for that reason, tend to experience more stress and consequently more psychosomatic reactions, in comparison to men (Kosmala-Anderson and Wallace 2007; Ribeiro et al. 2018). Also, in a recent study it was found that female medical students are more likely to worry more and feel more insecure about their skills which can lead them to study more and work more hours putting them at risk for experiencing higher levels of stress (Verdonk et al. 2014).

Additionally, while women used many of the same coping strategies as men, they seem to use mainly emotion-focused ones, which is in accordance with previous studies (e.g., Gefen and Fish 2012). Possible explanations may be linked to gender socialization, in which women are encouraged to seek support from others and to express more their emotions in comparison to men (Tamres et al. 2002). It is important to note, however, that health degrees are chosen primarily by women (Saavedra et al. 2010), so these differences may be due to higher prevalence of women in this study (84\%) and not solely to the characteristics of the degrees.

We found a direct effect of perceived stress on psychosomatic symptoms as expected and as found in previous studies (e.g., Ansari et al. 2014; Lee et al. 2011). This is not surprising since many of the psychosomatic reactions comprise symptoms that are consequences of the higher levels perceived, such as those related to the nervous, respiratory, muscular, and digestive systems (Pais-Ribeiro 2003). Concerning mediation results, our findings suggest that in addition to the direct effect of perceived stress on affect and psychosomatic symptoms, emotion dysregulation, and some coping strategies mediated this association. While some previous studies have 
Table 4 Results of the simple mediation analyses for emotion dysregulation

$\begin{array}{llllll}\text { Coeff } & \text { SE } & t & p & \text { LLCI } & \text { ULCI }\end{array}$

Perceived stress, emotion dysregulation and negative affect

Effects of perceived stress on emotion dysregulation (a path)

Effect of emotion dysregulation on negative affect (b path)

Total effect of perceived stress on negative affect (c path)

Direct effect of perceived stress on negative affect (c' path)

Coeff

$\mathrm{SE}$

$p \quad$ LLCI

ULCI

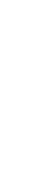

\begin{abstract}
Perceived stress, emotion dysregulation and positive affect
Effects of perceived stress on emotion dysregulation (a path)

Effect of emotion dysregulation on positive affect (b path)

Total effect of perceived stress on positive affect (c path)

Direct effect of perceived stress on positive affect (c' path)
\end{abstract}

Indirect effect of perceived stress on negative affect through emotion dysregulation

\begin{tabular}{|c|c|c|c|c|c|}
\hline 1.50 & .16 & -9.52 & .000 & -1.96 & .182 \\
\hline .13 & .03 & 4.18 & .000 & .068 & .188 \\
\hline .82 & .07 & 11.93 & .000 & .677 & .946 \\
\hline .62 & .08 & 7.75 & .000 & .461 & .776 \\
\hline Effect & Boo SE & & & $\begin{array}{l}\text { Boo } 95 \% \\
\text { LL }\end{array}$ & $\begin{array}{c}\text { Boo } 95 \% \\
\text { UL }\end{array}$ \\
\hline .19 & .05 & & & .096 & .307 \\
\hline 1.51 & .16 & 9.52 & .000 & 1.200 & 1.820 \\
\hline-.07 & .03 & -2.05 & .042 & -.129 & -.002 \\
\hline-.43 & .07 & -6.30 & .000 & -.570 & -.298 \\
\hline-.33 & .08 & -4.00 & .001 & -.500 & -.170 \\
\hline Effect & Boo SE & & & $\begin{array}{l}\text { Boo } 95 \% \\
\text { LL }\end{array}$ & $\begin{array}{c}\text { Boo } 95 \% \\
\text { UL }\end{array}$ \\
\hline-.10 & .05 & & & -.196 & -.009 \\
\hline 1.50 & .16 & 9.52 & .000 & 1.200 & 1.820 \\
\hline .33 & .15 & 2.21 & .028 & .035 & .624 \\
\hline 2.41 & .32 & 7.49 & .000 & 1.771 & 3.039 \\
\hline 1.91 & .39 & 4.90 & .000 & -1.140 & -2.680 \\
\hline Effect & Boo SE & & & $\begin{array}{l}\text { Boo } 95 \% \\
\text { LL }\end{array}$ & $\begin{array}{c}\text { Boo } 95 \% \\
\text { UL }\end{array}$ \\
\hline .50 & .27 & & & .027 & 1.094 \\
\hline
\end{tabular}

Indirect effect of perceived stress on positive affect through emotion dysregulation

Perceived stress, emotion dysregulation and psychosomatic symptoms

Effects of perceived stress on emotion dysregulation (a path)

Effect of emotion dysregulation on psychosomatic symptoms (b path)

Total effect of perceived stress on psychosomatic symptoms (c path)

Direct effect of perceived effect on psychosomatic symptoms (c' path)

Indirect effect of perceived stress on psychosomatic symptoms through emotion dysregulation

Coeff Coefficient, SE standard error, LLCI Lower level of the 95\% confidence intervals, ULCI Upper level of the 95\% confidence intervals, Boo Bootstrap results

suggested that coping and emotion regulation strategies could mediate the association between stress and some individuals' outcomes (Amaral et al. 2018; Compas et al. 2014; Gibbons et al. 2011; Saklofske et al. 2012), our findings are innovative in the sense that emotion dysregulation and some coping strategies significantly contributed to explain the association between perceived stress and affect and psychosomatic symptoms among university students.

In this study, positive reframing was the only coping strategy that accounts for explaining the link between perceived stress and positive affect. Thus, the ability to reframe more challenging experiences seems to contribute to improve students' affect. Positive reframe strategies that involve putting a positive spin on a stressful situation, seem to improve students' abilities to look at the stressful situation in a new way and to highlight new possibilities rather than the threats involved in it, promoting positive affect (e.g., Stoeber and Janssen 2011). Also, according to Jurist (2005), particular attention should be paid to the specific kind of strategies that involve revaluing (not just modulating), a process termed mentalized affectivity. We can hypothesise that positive reframing plays an important role in this process.
Emotion dysregulation also contributed to explain the link between perceived stress and affect and psychosomatic symptoms, as hypothesised. Emotion dysregulation is related to several psychopathologies (e.g., Aldao et al. 2010). Our findings seem to indicate that because students experience difficulties in regulating their emotions in response to stressful situations, they tend to experience less positive and more negative affect as well as more psychosomatic reactions. This is not surprising since previous studies have shown that mood and physical symptoms are strongly related to emotional states and how individuals regulate them (e.g., Escobar et al. 2010; Joormann and Stanton 2016). Indeed, experiencing stress to a greater extent can lead to difficulties in regulating it, enhancing the perception of psychological difficulties.

\section{Limitations and Future Research}

The findings from this study must be considered within the scope of its limitations. First, this is a cross-sectional study which limits conclusions regarding causality. Second, it relies on self-report questionnaires. Future studies should be conducted using other type of designs (longitudinal studies, 
diaries) and data collection (e.g., interviews). The number of females is much higher. For this reason, results regarding gender differences should be interpreted with caution. Future studies using larger and more heterogeneous samples should be conducted.

Moreover, at the present stage of our investigation, variables which are important sources of diversity in this institution, as a specific field of studies (e.g., Occupational Therapy, Radiology) and pedagogic model, remain to be analyzed. Still, it is our concern to follow this path at a later stage, thus the dominant focus on individual variables should not be regarded as a rejection of the systemic and ecological dimensions (Bronfenbrenner 1979; Menezes 1999). Hereafter, it would be relevant to find out if specific kinds of degrees influence results. Also, whether more student-centered pedagogic approaches, with a higher emphasis on soft skills building, such as Problem-based Learning (Macedo 2009), facilitate the development of more effective coping strategies.

\section{Clinical Implications}

This study has also clinical relevance. Considering that both personal and contextual factors influence the adaptation to higher education (Almeida et al. 2003), it is relevant to discuss how the psychosocial qualities that can turn learning and socializing institutions into developmentally adequate contexts can be promoted (Chaleta and Grácio 1998; Seco et al. 2007). Among many other short- and long-term strategic orientations, this important mission should encourage institutions to promote developmental programmes supporting the transition to higher education (Robotham 2008). Given our findings, these programmes should target coping and emotion regulation strategies to help these students to cope more effectively with stress and improve their quality of life by reducing their psychosomatic symptoms. As we found gender differences in terms of perceived stress and coping strategies, genderspecific programmes should be developed aimed at reducing psychosomatic symptoms, particularly among college females.

Additionally, given the important role of positive reframing for promoting positive affect when facing a stressful situation, these programmes should help students to counter negative thoughts with more positive ones, to think more positively, and to generate thoughts that help them to better cope with stressors or to focus on things that have been achieved by them. Considering that emotional dysregulation also played an important role in affect and psychosomatic symptoms, these programmes should also promote the development or the refinement of more effective ways to regulate emotions. This can include psychoeducation about emotions, development of strategies to recognise and label emotions, and promote their expression to significant others.
Data Availability Available under request.

\section{Compliance with Ethical Standards}

Conflicts of Interest/Competing Interests The authors declare no conflict of interests.

Code Availability (Software Application or Custom Code) Not applicable.

Ethical Approval Statement This study was approved by the Ethics Committee of $\|$ removed for blind review $\|$. Written informed consent was obtained from all participants.

\section{References}

Abdullah, M. C., Elias, H., Uli, J., \& Mahyuddin, R. (2010). Relationship between coping and university adjustment and academic achievement amongst first year undergraduates in a Malaysian public university. International Journal of Arts and Sciences, 3(11), 379-392.

Aldao, A., Nolen-Hoeksema, S., \& Schweizer, S. (2010). Emotionregulation strategies across psychopathology: A meta-analytic review. Clinical Psychology Review, 30, 217-237. https://doi.org/10. 1016/j.cpr.2009.11.004.

Almeida, L. S., Gonçalves, A., Salgueira, A. P., Machado, C., Fernandes, E., Machado, J., \& Vasconcelos, R. (2003). Expectativas de envolvimento académico à entrada na universidade: Estudo com alunos da Universidade do Minho [expectations of academic involvement at university entrance: An investigation with students from the University of Minho]. Psicologia: Teoria, Investigação e Prática, 8, 3-15.

Alzayyat, A., \& Al-Gamal, E. (2016). Correlates of stress and coping among Jordanian nursing students during clinical practice in psychiatric/mental health course. Stress and Health, 32(4), 304312. https://doi.org/10.1002/smi.2606.

Amaral, A. P., Soares, M. J., Pinto, A. M., Pereira, A. T., Madeira, N., Bos, S. C., Marques, M., Roque, C., \& Macedo, A. (2018). Sleep difficulties in college students: The role of stress, affect and cognitive processes. Psychiatry Research, 260, 331-337. https://doi.org/ 10.1016/j.psychres.2017.11.072.

Ansari, W. E., Oskrochi, R., \& Haghgoo, G. (2014). Are students' symptoms and health complaints associated with perceived stress at university? Perspectives from the United Kingdom and Egypt. International Journal of Environmental Research and Public Health, 11, 9981-10002. https://doi.org/10.3390/ijerph111009981.

Austin, E. J., Saklofske, D. H., \& Mastoras, S. M. (2010). Emotional intelligence, coping and exam-related stress in Canadian undergraduate students. Australian Journal of Psychology, 62, 42-50. https:// doi.org/10.1080/00049530903312899.

Beiter, R., Nash, R., McCrady, M., Rhoades, D., Linscomb, M., Clarahan, M., \& Sammut, S. (2015). The prevalence and correlates of depression, anxiety, and stress in a sample of college students. Journal of Affective Disorders, 173, 90-96. https://doi.org/10.1016/ j.jad.2014.10.054.

Bronfenbrenner, U. (1979). The ecology of human development: Experiments by nature and design. Cambridge, MA: Harvard University Press.

Brougham, R. R., Zail, C. M., Mendoza, C. M., \& Miller, J. R. (2009). Stress, sex differences, and coping strategies among college students. Current Psychology, 28, 85-97. https://doi.org/10.1007/ s12144-009-9047-0. 
Carlson, E., \& Voss, J. (2017). Using personal resilience techniques to reduce anxiety in university students. Western Journal of Nursing Research, 39, 1368-1368. https://doi.org/10.1177/ $0193945917715261 \mathrm{~d}$.

Carver, C. S. (1997). You want to measure coping but your protocol's too long: Consider the brief COPE. International Journal of Behavioral Medicine, 4, 92-100. https://doi.org/10.1207/s15327558ijbm0401_6.

Chaleta, M., \& Grácio, M. (1998). Intervenção com um grupo de estudantes do ensino superior: Desenvolvimento de competências pessoais e de aprendizagem [intervention with a group of students in higher education: Developing personal and learning skills]. Paper presented at the V Congresso Galaico-Português de Psicopedagogia, Braga: Universidade do Minho.

Chýlová, H., \& Natovová, L. (2012). Stress coping strategies at university students - part I: Gender differences. Journal on Efficiency and Responsibility in Education and Science, 5, 135-147. https://doi. org/10.7160/eriesj.2012.050303.

Cohen, S., Kamarck, T., \& Mermelstein, R. (1983). A global measure of perceived stress. Journal of Health and Social Behavior, 24, 385 396. https://doi.org/10.2307/2136404.

Coiro, M. J., Bettis, A. H., \& Compas, B. E. (2017). College students coping with interpersonal stress: Examining a control-based model of coping. Journal of American College Health, 65, 177-186. https://doi.org/10.1080/07448481.2016.1266641.

Compas, B. E., Jaser, S. S., Dunbar, J. P., Watson, K. H., Bettis, A. H., Gruhn, M. A., \& Williams, E. K. (2014). Coping and emotion regulation from childhood to early adulthood: Points of convergence and divergence. Australian Journal of Psychology, 66, 71-81. https://doi.org/10.1111/ajpy.12043.

Coutinho, J., Ribeiro, R., Ferreirinha, R., \& Dias, P. (2010). The Portuguese version of the difficulties in emotion regulation scale and its relationship with psychopathological symptoms. Revista de Psiquiatria Clínica, 37(4), 145-151. https://doi.org/10.1590/S010160832010000400001.

Deasy, C., Coughlan, B., Pironom, J., Jourdan, D., \& MannixMcNamara, P. (2014). Psychological distress and coping amongst higher education students: A mixed method enquiry. PLoS One, 9, e115193. https://doi.org/10.1371/journal.pone.0115193.

Dyson, R., \& Renk, K. (2006). Freshmen adaptation to university life: Depressive symptoms, stress, and coping. Journal of Clinical Psychology, 62, 1231-1244. https://doi.org/10.1002/jclp.20295.

Eisenberg, D., Hunt, J., \& Speer, N. (2013). Mental health in American colleges and universities. Journal of Nervous and Mental Disease, 201, 60-67. https://doi.org/10.1097/NMD.0b013e31827ab077.

Enns, A., Eldridge, G. D., Montgomery, C., \& Gonzalez, V. M. (2018). Perceived stress, coping strategies, and emotional intelligence: A cross-sectional study of university students in helping disciplines. Nurse Education Today, 68, 226-231. https://doi.org/10.1016/j. nedt.2018.06.012.

Escobar, J. I., Cook, B., Chen, C. N., Gara, M. A., Alegría, M., Interian, A., $\&$ Diaz, E. (2010). Whether medically unexplained or not, three or more concurrent somatic symptoms predict psychopathology and service use in community populations. Journal of Psychosomatic Research, 69, 1-8. https://doi.org/10.1016/j.jpsychores.2010.01.001.

Extremera, N., \& Rey, L. (2015). The moderator role of emotion regulation ability in the link between stress and well-being. Frontiers in Psychology, 6, 1632. https://doi.org/10.3389/fpsyg.2015.01632.

Fernandez, R., Salamonson, Y., \& Griffiths, R. (2012). Emotional intelligence as a predictor of academic performance in first-year accelerated graduate entry nursing students. Journal of Clinical Nursing, 21, 3485-3492. https://doi.org/10.1111/j.1365-2702.2012.04199.x.

Folkman, S. (2010). Stress, coping, and hope. Psycho-Oncology, 19, 901-908. https://doi.org/10.1002/pon.1836.

Frazier, P., Gabriel, A., Merians, A., \& Lust, K. (2019). Understanding stress as an impediment to academic performance. Journal of
American College Health, 67, 562-570. https://doi.org/10.1080/ 07448481.2018.1499649.

Galinha, I. C., \& Pais-Ribeiro, J. L. (2005). Contribuição Para o estudo da versão Portuguesa da positive and negative affect schedule (PANAS): II - Estudo psicométrico [Contribution to the study of the Portuguese version of the positive and negative affect schedule (PANAS): II Psychometric study]. Análise Psicológica, 2, 219-227.

Gefen, D. R., \& Fish, M. C. (2012). Gender differences in stress and coping in first-year college students. Journal of College Orientation, Transition, and Retention, 19, 10.24926/ jcotr.v19i2.2797.

Gibbons, C., Dempster, M., \& Moutray, M. (2011). Stress, coping and satisfaction in nursing students. Journal of Advanced Nursing, 67(3), 621-632. https://doi.org/10.1111/j.1365-2648.2010.05495.x.

Gratz, K. L., \& Roemer, L. (2004). Multidimensional assessment of emotion regulation and dysregulation: Development, factor structure, and initial validation of the difficulties in emotion regulation scale. Journal of Psychopathology and Behavioral Assessment, 26, 41-54. https://doi.org/10.1007/s10862-008-9102-4.

Gross, J. J. (1998). The emerging field of emotion regulation: An integrative review. Review of General Psychology, 2, 271-299.

Hayes, A. F. (2015). Introduction to mediation, moderation, and conditional process analysis: A regression-based approach. New York: Guilford publications.

Heinen, I., Bullinger, M., \& Kocalevent, R. D. (2017). Perceived stress in first year medical students-associations with personal resources and emotional distress. BMC Medical Education, 17, 4. https://doi.org/ 10.1186/s12909-016-0841-8.

Joormann, J., \& Stanton, C. H. (2016). Examining emotion regulation in depression: A review and future directions. Behaviour Research and Therapy, 86, 35-49. https://doi.org/10.1016/j.brat.2016.07.007.

Jurist, E. L. (2005). Mentalized affectivity. Psychoanalytic Psychology, 22, 426-444. https://doi.org/10.1037/0736-9735.22.3.426.

Kadzikowska-Wrzosek, R. (2012). Perceived stress, emotional ill-being and psychosomatic symptoms in high school students: The moderating effect of self-regulation competences. Archives of Psychiatry and Psychotherapy, 3, 25-33.

Kenny, D. A. (2017). MedPower: An interactive tool for the estimation of power in tests of mediation [Computer software]. Available from https://davidakenny.shinyapps.io/MedPower/

Kosmala-Anderson, J., \& Wallace, L. M. (2007). Gender differences in the psychosomatic reactions of students subjected to examination stress. Electronic Journal of Research in Educational Psychology, $5,325-334$.

Lafrance Robinson, A., Kosmerly, S., Mansfield-Green, S., \& Lafrance, G. (2014). Disordered eating behaviours in an undergraduate sample: Associations among gender, body mass index, and difficulties in emotion regulation. Canadian Journal of Behavioural Science, 46, 320-326. https://doi.org/10.1037/a0031123.

Larcombe, W., Finch, S., Sore, R., Murray, C. M., Kentish, S., Mulder, R. A., Lee-Stecum, P., Baik, C., Tokatlidis, O., \& Williams, D. A. (2016). Prevalence and socio-demographic correlates of psychological distress among students at an Australian University. Studies in Higher Education, 4, 1074-1091. https://doi.org/10.1080/ 03075079.2014.966072.

Lazarus, R. S., \& Folkman, S. (1984). Stress, appraisal, and coping. New York: Springer Publishing Company.

Lee, E. Y., Mun, M. S., Lee, S. H., \& Cho, H. S. M. (2011). Perceived stress and gastrointestinal symptoms in nursing students in Korea: A cross-sectional survey. BMC Nursing, 10, 22. https://doi.org/10. 1186/1472-6955-10-22.

Linnenbrink, E. A. (2007). The role of affect in student learning. In P. A. Schutz \& R. Pekrun (Eds.), Emotion in education (pp. 107-124). Burlington, MA: Elsevier.

Macedo, R. (2009). Concepç̃es e sentimentos em relação à Aprendizagem Baseada em Problemas (APB): Estudo do caso dos estudantes de 
Fisioterapia da Escola superior de Tecnologia da Saúde do Porto [conceptions and feelings about the problem-based learning (PBL): Case study of the students of physical therapy at School of Allied Health Sciences of Oporto]. EssFisiOnline, 2, 34-54.

Menezes, I. (1999). Desenvolvimento psicológico na formação pessoal e social [Psychological development in personal and social education]. Porto: Asa.

Monat, A., Lazarus, R., \& Reevy, G. (2007). The Praeger handbook on stress and coping (Vol. vol.2). Westport, CT: Praeger Publishers/ Greenwood Publishing Group.

Morrison, R., \& O'Connor, R. C. (2005). Predicting psychological distress in college students: The role of rumination and stress. Journal of Clinical Psychology, 61(4), 447-460. https://doi.org/10.1002/ jclp.20021.

Nunnally, J., \& Bernstein, I. (1994). Psychometric theory (3rd ed.). New York: McGraw Hill.

Othman, N., Ahmad, F., El Morr, C., \& Ritvo, P. (2019). Perceived impact of contextual determinants on depression, anxiety and stress: A survey with university students. International Journal of Mental Health Systems, 13, 17. https://doi.org/10.1186/s13033-019-0275-x.

Pais-Ribeiro, J. L. (2003). Estudo de adaptação do Questionário de Manifestações Físicas de Mal Estar [Adaptation Study of the Physical Manifestations of Discomfort Questionnaire]. Psiquiatria Clínica, 24, 65-76.

Pais-Ribeiro, J. L., \& Marques, T. (2009). A avaliação do stresse: A propósito de um estudo de adaptação da escala de percepção de stresse [The evaluation of stress: About an adaptation study of the perceived stress scale]. Psicologia, Saúde \& Doenças, 10, 237-248.

Pais-Ribeiro, J. L., \& Rodrigues, A. P. (2004). Questões acerca do coping: A propósito do estudo de adaptação do brief COPE [questions about coping: About the adaptation study of the brief COPE]. Psicologia, Saúde \& Doenças, 5(1), 3-15.

Parker, J. D. A., Hogan, M. J., Eastabrook, J. M., Oke, A., \& Wood, L. M. (2006). Emotional intelligence and student retention: Predicting the successful transition from high school to university. Personality and Individual Differences, 41, 1329-1336. https://doi.org/10.1016/j. paid.2006.04.022.

Ribeiro, I. J., Pereira, R., Freire, I. V., de Oliveira, B. G., Casotti, C. A., \& Boery, E. N. (2018). Stress and quality of life among university students: A systematic literature review. Health Professions Education, 4, 70-77. https://doi.org/10.1016/j.hpe.2017.03.002.

Robotham, D. (2008). Stress among higher education students: Towards a research agenda. Higher Education, 56, 735-746. https://doi.org/ 10.1007/s10734-008-9137-1.

Saavedra, L., Taveira, M. C., \& Silva, A. D. (2010). A subrepresentatividade das mulheres em áreas tipicamente masculinas: Factores explicativos e pistas Para a intervenção [the under representation of women in typically male areas: Explanatory factors and avenues for intervention]. Revista Brasileira de Orientação Profissional, 11, 49-59.

Saïas, T., Du Roscoät, E., Véron, L., Guignard, R., Richard, J. B., Legleye, S., et al. (2014). Psychological distress in French college students: demographic, economic and social stressors. Results from the 2010 National Health Barometer. BMC Public Health, 14(1), 256. https://doi.org/10.1186/1471-2458-14-256.

Saklofske, D. H., Austin, E. J., Mastoras, S. M., Beaton, L., \& Osborne, S. E. (2012). Relationships of personality, affect, emotional intelligence and coping with student stress and academic success: Different patterns of association for stress and success. Learning and Individual Differences, 22, 251-257.

Sánchez-Gelabert, A., Figueroa, M., \& Elias, M. (2017). Working whilst studying in higher education: The impact of the economic crisis on academic and labour market success. European Journal of Education, 52, 232-245. https://doi.org/10.1111/ejed.12212.

Sasaki, M., \& Yamasaki, K. (2007). Stress coping and the adjustment process among university freshmen. Counselling Psychology Quarterly, 20(1), 51-67. https://doi.org/10.1080/ 09515070701219943.

Seco, G., Dias, M. I., Pereira, M. I., Casimiro, M., \& Custódio, S. (2007). Construindo pontes para uma adaptação bem sucedida ao ensino superior: Implicações práticas de um estudo [Building bridges for successful adaptation to higher education: Practical Implications of a study]. Paper presented at the IX Congresso da Sociedade Portuguesa de Ciências da Educação, Madeira.

Seyedfatemi, N., Tafreshi, M., \& Hagani, H. (2007). Experienced stressors and coping strategies among Iranian nursing students. BMC Nursing, 6, 11-21. https://doi.org/10.1186/1472-6955-6-11.

Shi, M., Liu, L., Wang, Z. Y., \& Wang, L. (2015). Mediating role of resilience in the relationship between big five personality and anxiety among Chinese medical students: A cross sectional study. PLoS One, 10, 1-12. https://doi.org/10.1371/journal.pone.0119916.

Stallman, H. M. (2010). Psychological distress in university students: A comparison with general population data. Australian Psychologist, 45, 249-257. https://doi.org/10.1080/00050067.2010.482109.

Stoeber, J., \& Janssen, D. P. (2011). Perfectionism and coping with daily failures: Positive reframing helps achieve satisfaction at the end of the day. Anxiety, Stress \& Coping, 24, 477-497. https://doi.org/10. 1080/10615806.2011.562977.

Suldo, S. M., Shaunessy, E., \& Hardesty, R. (2008). Relationships among stress, coping, and mental health in high-achieving high school students. Psychology in the Schools, 45(4), 273-290. https://doi.org/10. 1002/pits.20300.

Tamres, L. K., Janicki, D., \& Helgeson, V. S. (2002). Sex differences in coping behavior: A meta-analytic review and an examination of relative coping. Personality and Social Psychology Review, 6, 230. https://doi.org/10.1207/S15327957PSPR0601_1.

Verdonk, P., Räntzsch, V., de Vries, R., \& Houkes, I. (2014). Show what you know and deal with stress yourself: A qualitative interview study of medical interns' perceptions of stress and gender. $B M C$ Medical Education, 14, 96. https://doi.org/10.1186/1472-6920-1496.

Watson, D., Clark, L. A., \& Tellegen, A. (1988). Development and validation of brief measures of positive and negative affect: The PANAS scales. Journal of Personality and Social Psychology, 54, 1063-1070. https://doi.org/10.1037//0022-3514.54.6.1063.

Weinberg, A., \& Klonsky, E. D. (2009). Measurement of emotion dysregulation in adolescents. Psychological Assessment, 21, 616-621. https://doi.org/10.1037/a0016669.

Wranik, T., Barrett, L. F., \& Salovey, P. (2007). Intelligent emotion regulation. In J. Gross (Ed.), Handbook of emotion regulation (pp. 393-428). New York: Guilford.

Yildiz, M. A. (2017). Pathways to positivity from perceived stress in adolescents: Multiple mediation of emotion regulation and coping strategies. Current Issues in Personality Psychology, 5, 272-284. https://doi.org/10.5114/cipp.2017.67894.

Zahniser, E., \& Conley, C. S. (2018). Interactions of emotion regulation and perceived stress in predicting emerging adults' subsequent internalizing symptoms. Motivation and Emotion, 42, 763-773. https://doi.org/10.1007/s11031-018-9696-0.

Publisher's Note Springer Nature remains neutral with regard to jurisdictional claims in published maps and institutional affiliations. 